\title{
Occupational Hazards Associated with Welding Work That Influence Health Status of Welders
}

\section{Mayur Bhaskarrao Wanjari ${ }^{1}$, Pratibha Wankhede ${ }^{2}$}

Section: Healthcare

Sci. Journal Impact

Factor: 6.1 (2018)

ICV: 90.90 (2018)

(c) (i) (3)

Copyright@IJCRR

\begin{abstract}
'MSc Nursing, Department Community Health Nursing, Smt. Radhikabai Meghe College of Nursing, Datta Meghe lnstitute of Medical Science (Deemed to be University), Sawangi (M), Wardha, Maharashtra, India; ${ }^{2}$ Assistant Professor, Department Community Health Nursing, Smt. Radhikabai Meghe College of Nursing, Datta Meghe Institute of Medical Science (Deemed to be University), Sawangi (M), Wardha, Maharashtra, India.
\end{abstract}

\section{ABSTRACT}

Welding apprentices invest in their vocational and technical training. The welding job has numerous risk factors, including physical, chemical, and psychological. Exposure to these conditions may contribute to specific health problems and occupational hazards. Most welders learned to weld by apprenticeship, without any structured educational system in health and safety and a small number of welders is trained by trainers and certification course. Among some of the health-related problems that are led by welding work are skin burn, lung diseases, eye problems, hearing problems, heart problems, and musculoskeletal disorder. Welding work has various occupational health hazards because of the lack of using personal protective equipment. Personal protective equipment is a significant contributor to the prevention of various occupational health hazards. Physical morbidity profile of welders estimated 562000 employees are at risk for exposure to chemical and physical hazards according to Occupational Safety and Health Administration research. In 1993, the Bureau of Labor Statistics reported 58 deaths from welding and cutting accidents involving fires, electrocutions, asphyxiation, falls, and crushing injuries. Present overview of physical morbidity of welders are a low number of Publications about apprentices welding are a requirement for knowledge improving and give health promotion education to welders.

Key Words: Certification, Hazard, Personal protective equipment, Risk factor, Training program, Welding apprentices

\section{INTRODUCTION}

Welding is a fabrication process whereby two or more parts are fused using heat. When two pieces to be joined are melted, heat or pressure or both are applied and with or without metal attached to form a metal bond. ${ }^{1}$ In India, numerous examinations in the past have centred around medical problems of welders utilized at sorted out divisions, with insignificant thoughtfulness regarding those utilized in the disorderly welding sectors. ${ }^{2,3}$ With expanding sloppy Welding units in urban India with minimal available welding knowledge, it is imperative to comprehend the diverse spectra of medical issues among them to give data to design proper mediations and to build consciousness of potential wellbeing dangers. ${ }^{4}$

Constrained examinations can be found in word related wellbeing ${ }^{5,6}$ and among welders. ${ }^{5}$ While welders are presented to the dangerous work and the work of wellbeing measures in addition to the low use of PPE, it is important to discover the latest medical conditions of these welders. ${ }^{7}$

\section{RISK FACTORS}

Security in welding is a critical consideration in any welding work. Just Arc welding is the best profession when using the necessary personal protection equipment. Although, if security precautions are stopped, welder's health is potentially dangerous in that condition, including electrical shock, burns, fumes and gases, explosion. ${ }^{8}$ Some organizations work for welders to keep them safe from occupational hazards like the American Conference of Governmental Industrial Hygienists (ACGIH) and the Occupational Safety and Health Administration (OSHA) ${ }^{9,10}$ This type of organization works for welders they want to prevent occupational health hazards among welders and minimize the rate of occurrences. They provide employers with guidance to ensure that all

\section{Corresponding Author:}

Mayur Wanjari, Smt. Radhikabai Meghe College of Nursing, Datta Meghe Institute of Medical Science (Deemed to be University), Wardha, Maharashtra, India; Phone: +93 08007386204; Email: wanjari605@gmail.com

ISSN: 2231-2196 (Print)

Received: 15.06 .2020
ISSN: 0975-5241 (Online)

Revised: 05.09 .2020
Accepted: 14.10 .2020 
employees can monitor the workforce by following critical guidance. ${ }^{11}$

Risk factors of welders according to the Conference of Governmental Industrial Hygienists (ACGIH) and the Occupational Safety and Health Administration (OSHA).

\section{Electrical shock}

The welder faces the most frequent serious and immediate risk cause of electrical shock. Electric shock can cause serious injury or death. ${ }^{12}$ Electrical shock occurs when welders accidentally touch open wires or open wire connected to an object that has a voltage between them. If the worker keeps a raw wire in one hand, the electrical current flows through the wire and welding machine in another hand it can lead to death and serious problem for welders. ${ }^{13}$

\section{Fumes and gases}

It is most usual in welding practice that excessive contact with welding gases and gasses may present a danger to the safety of welders. ${ }^{12}$ Welding fumes contain a Seriously damaging large amount of compounds made from metal oxides welding material or welding process, according to this situation OSHA given guidelines for that keep Use sufficient ventilation and emissions in the work environment to monitor toxic smoke and gasses exposure, it depends on which material used for the welding process. ${ }^{14}$ Welding is required adequate ventilation in the workplace to hold gases and gasses from the respiration cycle and general environment.

\section{Flames and fires}

The welding process produces high temperatures which may be sufficient if proper safety procedures or personal protection devices are not used. ${ }^{15}$ While the welding process may lead temperature of 10,000 degrees Fahrenheit, but the danger is not the welding process, danger when that contact with object and spike to explosion. ${ }^{14}$ This can go as far as 300 meters from the weld zone. Install fire alarm for security to prevent this condition and also save human life. ${ }^{16}$

\section{Injuries from insufficient practices and PPE}

Injuries from welding are common because welding work welders will deal with various situations and physical exertion. In that major role play personal protective equipment (PPE) for welders to keep free from welding hazards. Such as one of the most common burn-in welding accidents, the proper use of PPE gives the welders liberty adequate protection from welding hazards. ${ }^{17}$

\section{Health Hazards}

According to TWI welding association and research institute and Occupational Safety and Health Administration (OSHA) health hazards are classified. ${ }^{18}$ According to research Annually, 40-50 welders are hospitalized come to the respiratory problems borne out by welding fumes, every year 2 of those welders die. Annually Nine welders suffered from workrelated problems of asthma, stainless steel fumes contain harmful chromium oxide $\left(\mathrm{Cr}_{2} \mathrm{O}_{3}\right)$ and nickel oxide $(\mathrm{NiO})$. Welding fumes are highly carcinogenic to humans.

\section{Respiratory IIIness}

Several studies reported that respiratory illness is more common in welders and morbidity rate also in large numbers. ${ }^{19}$

- Pneumonia- Welders are much more likely to be suffering respiratory infection that can cause serious and very often deadly pneumonia. While a new generation of modern antibiotics usually cures rapidly the infection. Serious trigger results in the hospitalization of 40-50 welders each year of cases 2 being deadly. ${ }^{20}$

- Occupational asthma- Around Nine welders' workers affect asthma very terribly per year. The resent HSE research found that welding worker fumes Could not be predisposed to trigger asthma. Even now HSE counseling welders safeguard oneself and control the welding vapours to reduce the rate of infection probable. ${ }^{21}$

- Cancer-The welding gases are listed worldwide as carcinogenic to humans. But probably related to stainless steel welding. ${ }^{22}$

- Metal fume fever- recent studies show the morbidity of metal fume fever is $43.7 \%$ of welding workers get an infection. In welders show symptoms like malaise, chills, dry cough, shortness of breath showed after when exposure is more than 3-10 hours and its resolve in 24 to 48 hours. ${ }^{21}$

- Irritation of throat and lungs- Accordance to studies of metal fume fever and respiratory symptoms related to welding May have been an indicator for presenting signs of respiratory illness but never for physiological disorders in welders. Gasses or small debris in welding gases cause dry throat and coughing.

- Temporarily reduce Pulmonary Function-Overall normal lung volume, as well as lung peak flow, were also affected by prolonged exposure to welding fumes, but this effect is not long term. ${ }^{22}$

Noise: Apart from TIG- welding, electromagnetic welding mostly creates a dangerous sound level. ${ }^{21}$ Hearing problem is reported as welders are decrease hearing after exposure to noise from welding work. $35.7 \%$ of welder suffer from welding-related hearing problems. ${ }^{21}$ 
Musculoskeletal problems: Symptoms revealed welder's lower back pain, muscle pain that they suffer from various serious problems. ${ }^{22}$ Musculoskeletal problems are notified $46.7 \%$ in research studies.

\section{Skin problems}

Welders are more prone to skin related problems, as reported symptoms of skin irritation and erythema, as shown in the research study. Skin diseases are seen in welders $74.3 \%$ is many scores of skin problems and most of the welders is suffering from a burn due to the inability of handling welding equipment. $^{21}$

\section{RISK ASSESSMENT}

In a research study, find out a risk analysis of welders by using an analysis of eight metals assessment of comet and micronucleus harm by ICP-MS in blood and urine and DNA. The welders were exposed in that basic features from 0.5 to 45 years..$^{23}$ In a developing country, they are using the latest technologies and protective devices to prevent occupational hazards. The ninety per cent upper band cancer incidence related to exposure to hexavalent chromium and nickel was $6.03 \mathrm{E}-03$ to $2.12 \mathrm{E}-02$ and $7.18 \mathrm{E}-03$ to $2.61 \mathrm{E}-02$, respectively. The study of this scenario shows that asthma symptoms health threat in welders is much more important. Welders are at high risk of cancer. ${ }^{24}$

Based on previous research, cancer risk estimation was calculated. It can range from 1 to over 40 years. Some instances were recorded with 36 years of experience as a welder. In certain academic reports, however, there are cases of 40 years of professional experience in welding the research-based study. ${ }^{25}$ This point can be viewed as a significant consideration in recruitment and screening tests. The asthmatic patient to have higher ventilation rate and breathing rate comparison with the normal subject. ${ }^{26}$

The basic steps in risk assessment. ${ }^{27}$

1. Identify the hazardous situation.

2. Consider who maybe suffer in the situation and how

3. Evaluation of risk may arise from hazards, and whether established safety precautions must be implemented and sufficient.

4. Record observations, even if they are easy to explain.

5. Review the evaluation from moment to moment and revise where required.

\section{PREVENTIVE MEASURES}

In other research, there was recognition of the workplace safety risks involved with welding between $77.9 \%$ and $91.6 \%$ of welders. The period prevalence of morbidity of welders according to the survey, many welders have noted an adherence to occupational health hazards and non-use of the protective equipment. Health awareness of welders and health measures or recommendations also had to be carried out at the welding site. ${ }^{28}$ Many of the preceding studies did not thoroughly assess the morbidity trend among welders. Also, past studies indicated a lack of awareness of occupational hazards and the use of safety precautions by many welders. ${ }^{29}$ Few types of research showed a high degree of concern within welders regarding occupational hazards, even so, their use of safety equipment did not affect them. It was, therefore, crucial for us to analyze the awareness and purposes for the non-use of protective equipment among the welders. ${ }^{30}$

\section{EPIDEMIOLOGY}

Morbidity classification found $21.3 \%$ of welders and $6 \%$ of non-welders have at minimum one morbidity, including hypertension or diabetes. There was recorded hypertension among $19(12.6 \%)$ welders as well as $1(0.7 \%)$ non-welder. ${ }^{31}$ An engagement of younger age groups indicates an early age internship at the start of the job through hands-on coaching from trained welders. Approximately $85.3 \%$ of respondents were married, a stronger correlation in India. ${ }^{32}$ Frequent self-reported effects after injuries included skin conditions $(74.3 \%)$, and arc-related issues (61.3\%), asthma complications $(46.7 \%)$, while the least frequent condition was hearing difficulties (35.7\%). Skin, eye, and respiratory morbidity are among the common health hazards that have been associated with several studies. ${ }^{33}$

In this study, metal fume-related symptoms (43.3\%) are like the $43.8 \%$ Isah finding. Likewise, in this other research in Ethiopia, the incidence of arc eye symptoms was reported at $36 \%{ }^{34} 119(76.8 \%)$ was injured, the other most prevalent morbidity between many respondents. Two of the participants have had no morbidity in the last year. A minimum of 20 welders (12.9\%) had no ocular morbidity. A minimum of 38 welders $(24.5 \%)$ has suffered through work-related illnesses over the past month. In the following months, the average value of work-related illnesses was $3.5 \pm 2.8(95 \% \mathrm{CI}$ 2.6101-4.4425). It fluctuated from 1 to 10 illnesses. Six of such welders experienced a single incident, ${ }^{33}$ encountered 2 episodes, 7 experienced 3 incidents, 4 experienced 4 occurrences and 8 experienced 5 occurrences. That many welders, $13(34.2 \%)$ out of 38 , found two disorders in the following months. Two staff each reported co-morbidities such as renal stones, hypertension, and diabetes. ${ }^{35}$

\section{DISCUSSION}

Occupation hazards among welders due to inadequate use of PPE. Most of the welders use recommended PPE to find 
by Bhumika et al. and Kumar SG et al. ${ }^{28}$ In welders musculoskeletal disorders occur due to poor condition of the workplace. Working in healthy body condition, using appropriate PPE under working conditions. Reduce the repetition of the same work that maybe reduce the risk of musculoskeletal disorders. Burns and electrical shock are more likely to occur among workers exposed to welding because of the accidental worker touches the welding electrode with bare hand and amount of heat as well as the pressure used in the process. ${ }^{36}$ Lack of safety training about occupational hazards, limited use of PPE and prolong working hours are contributing factors to the occurrence of injuries. ${ }^{37}$ Hence, make criteria with educational qualification during recruitment, a compulsory training course on welding, at least PPE awareness program is recommended to all employee.

\section{CONCLUSION}

Though some publications have been found also on subject and should be noted that too many studies have been carried out in developed countries, the prevalence of morbidity among the welder's survey respondents was large. Several welders have reported ignorance of health problems associated with the profession and non-use of safety equipment. Welding initiatives are still in India, but weak welding units' industries are declining to conform with national standards. This brings in for powerful endeavours by the concerned specialists to implement capability rule and pre-position preparing programs for welders, a specific test in a creating nation, for example, India. In any case, mandatory transitional instructional training in welding and the use of a PPEAwareness system are required.

\section{ACKNOWLEDGMENT}

Authors acknowledge the immense help received from the scholars whose articles are cited and included in references to this manuscript. The authors are also grateful to authors / editors / publishers of all those articles, journals, and books from which the literature for this article has been reviewed and discussed.

\section{Conflict of Interest: Nil}

\section{Funding/Support}

The authors are grateful for financial support of Datta Meghe Institute of Medical Science (Deemed to be University), Sawangi (M), Wardha, India

\section{REFERENCES}

1. Ashby HS. Welding fume in the workplace. Professional Safety. 2002 Apr 1;47(4):55-63.
2. Wittczak T, Dudek W, Walusiak-Skorupa J, ŚwierczyńskaMachura D, Cader W, Kowalczyk M, et al. Metal-induced asthma and chest X-ray changes in welders. Int J Occup Med Environ Health 2012 Jun;25(3):242-50.

3. Husain T, Rastogi SK, Gupta BN, Mathur N. Spirometric abnormalities among welders. Epidememiology 2004 Jul;15(4): S168.

4. Sabitu K, Iliyasu Z, Dauda MM. Awareness of occupational hazards and utilization of safety measures among welders in Kaduna metropolis, Northern Nigeria. Annals African Med 2009 Jan;8(1):46.

5. Antonini JM, Santamaria AB, Jenkins NT, Albini E, Lucchini $R$. Fate of manganese associated with the inhalation of welding fumes: potential neurological effects. Neurotoxicology 2006 May;27(3):304-10.

6. Woskie SR, Kalil A, Bello D, Virji MA. Exposures to quartz, diesel, dust, and welding fumes during heavy and highway construction. AIHA J 2002 Jul;63(4):447-57.

7. Peng CY, Lan CH, Juang YJ, Tsao TH, Dai YT, Liu HH, et al. Exposure assessment of aluminum arc welding radiation. Health Physics 2007 Oct;93(4):298-306.

8. Smargiassi A, Baldwin M, Savard S, Kennedy G, Mergler D, Zayed J. Assessment of exposure to manganese in welding operations during the assembly of heavy excavation machinery accessories. Appl Occup Env Hyg 2000 Jan;15(10):746-50.

9. Cloe WW. Selected Occupational Fatalities Related to Welding and Cutting as Found in Reports of OSHA Facility/catastrophe Investigations. US Department of Labor, Occupational Safety and Health Administration; 1988.

10. Spear JE. Welding Safety: Assessing and Controlling Exposure to Hexavalent Chromium. Profess Safety 2010 Sep ;55(09):2231 .

11. Stephenson D, Seshadri G, Veranth JM. Workplace exposure to submicron particle mass and number concentrations from manual arc welding of carbon steel. AIHA J 2003 Jul;64(4):516-21.

12. Antonini JM, Lewis AB, Roberts JR, Whaley DA. Pulmonary effects of welding fumes: review of worker and experimental animal studies. Am J Indust Med 2003 Apr;43(4):350-60.

13. Antonini JM, Taylor MD, Zimmer AT, Roberts JR. Pulmonary responses to welding fumes: role of metal constituents. J Toxicol Environ Health, Part A. 2004 Feb;67(3):233-49.

14. Jenkins NT, Eagar TW. Chemical analysis of welding fume particles. Welding J 2005 Jun;84(6):87.

15. Ellingsen DG, Dubeikovskaya L, Dahl K, Chashchin M, Chashchin V, Zibarev E, et al. Air exposure assessment and biological monitoring of manganese and other major welding fume components in welders. J Environ Monit 2006;8(10):1078-86.

16. Golbabaei F, Seyedsomea M, Ghahri A, Shirkhanloo H, Khadem M, Hassani H, et al. Assessment of welder's exposure to carcinogen metals from manual metal arc welding in gas transmission pipelines, Iran. Iranian J Public Health 2012;41(8):61.

17. Lemieux CL, Long AS, Lambert IB, Lundstedt S, Tysklind M, White PA. Cancer risk assessment of polycyclic aromatic hydrocarbon contaminated soils determined using bioassay-derived levels of benzo [a] pyrene equivalents. Environ Sci Tech 2015 Feb;49(3):1797-805.

18. Sjögren B, Hansen KS, Kjuus H, Persson PG. Exposure to stainless steel welding fumes and lung cancer: a meta-analysis. Occupat Environ Med 1994 May;51(5):335-6.

19. Kesten S, Maleki-Yazdi MR, Sanders BR, Wells JA, McKillop SL, Chapman KR, et al. Respiratory rate during acute asthma. Chest 1990 Jan;97(1):58-62.

20. Santillan AA, Camargo CA, Colditz GA. A meta-analysis of asthma and risk of lung cancer (United States). Cancer Causes \& Cont. 2003 May 1;14(4):327-34. 
21. United States Environmental Protection Agency. Guidelines for Carcinogen Risk Assessment US Environmental Protection Agency, Washington, DC, EPA/630/P-03/001F.

22. Doull J, Cattley R, Elcombe C, Lake BG, Swenberg J, Wilkinson $\mathrm{C}$, et al. A cancer risk assessment of di (2-ethylhexyl) phthalate: application of the new US EPA Risk Assessment Guidelines. Reg Tox Pharmac 1999 Jun;29(3):327-57.

23. Muromtsev BI, Turkov II. Peculiarities of welding procedure for tubes of steel-08Kh22N6T (EhP-53). Tekhnologicheskie Osobennosti 08Kh22N6T (EhP-53).

24. Hansen KS, Lauritsen JM, Skytthe A. Cancer incidence among mild steel and stainless steel welders and other metal workers. Am J Ind Med 1996 Oct;30(4):373-82.

25. Mannetje A, Brennan P, Zaridze D, Szeszenia-Dabrowska N, Rudnai P, Lissowska J, et al. Welding and lung cancer in Central and Eastern Europe and the United Kingdom. Am J Epidemiol 2012; 175:706-14.

26. Bradshaw LM, Fishwick D, Slater T, Pearce N. Chronic bronchitis, work-related respiratory symptoms, and pulmonary function in welders in New Zealand. Occup Environ Med 1998; 55:150-54.

27. Reese CD, Eidson JV. Handbook of OSHA construction safety and health. Crc Press; 2006 Mar 23.

28. Kumar SG, Dharanipriya A, Kar SS. Awareness of occupational injuries and utilization of safety measures among welders in coastal South India. Int J Occup Environ Med 2013 Oct $15 ; 4: 252-172$.

Table 1: Welding Hazards

\section{Hazards}

1. Fumes and gases

2. Electrical shock

3. Radiation

4. $\quad$ Noise

5. $\quad$ Fire and Burns
29. Isah EC, Okojie OH. Occupational health problems of welders in Benin City, Nigeria. J Med Biomed Res 2006; 5:64-69.

30. Jani V, Mazumdar VS. Prevalence of respiratory morbidity among welders in unorganized sector of Baroda city. Ind J Occup Environ Med 2004; 8:16-21.

31. Sabitu K, Iliyasu Z, Dauda MM. Awareness of occupational hazards and utilization of safety measures among welders in kaduna metropolis, Northern Nigeria. Ann Afr Med 2009; 8:46-51.

32. Chobanian AV, Bakris GL, Black HR, Cushman WC, Green LA, Izzo JL, et al. The Seventh Report of the Joint National Committee on Prevention, Detection, Evaluation, and Treatment of High Blood Pressure: The JNC 7 Report. JAMA 2003; 289:2573-5.

33. Budhathoki SS, Singh SB, Niraula SR, Pokharel PK. Morbidity patterns among the welders of eastern Nepal: a cross-sectional study. Ann Occup Env Med 2016 Dec;28(1):62.

34. Fiebai B, Awoyesuku EA. Ocular injuries among industrial welders in Port Harcourt, Nigeria. Clin Ophth (Auckland, NZ). 2011; 5:1261.

35. Blair A, Walrath J, Rogot E. Mortality patterns among US veterans by occupation. I. Cancer. J Nat Cancer Inst 1985 Dec;75(6):1039-47.

36. Raphela SF. Occupational injuries among workers in a welding company within Mangaung Metropolitan Municipality. Occ Health Southern Africa 2015 Sep;21(5):8-11.

37. Bogale D, Tefera W. Assessment of occupational injuries among Addis Ababa city municipal solid waste collectors: a cross-sectional study. BMC Public Health 2014 Dec;14(1):169. 